\title{
Integrated process for recovery of rare-earth elements from lamp phosphor waste using methanesulfonic acid
}

\author{
Nerea Rodriguez Rodriguez,,$^{\dagger *}$ Brent Grymonprez, ${ }^{\dagger}$ Koen Binnemans ${ }^{\dagger}$ \\ ${ }^{\dagger}$ KU Leuven, Department of Chemistry, Celestijnenlaan 200F, P.O. box 2404, B-3001 Leuven, \\ Belgium.
}

*Corresponding author:

Email: nerea.rodriguezrodriguez@kuleuven.be

Number of pages: 3

Number of figures: 3

Number of tables: 0 


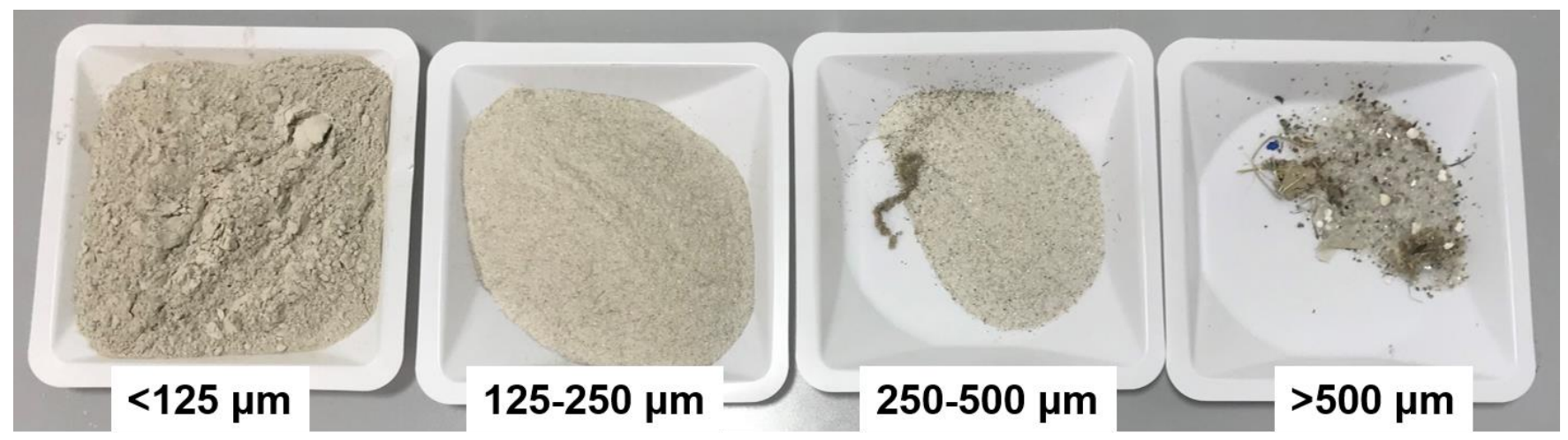

Figure S1: Four different fractions after sieving the phosphor waste.

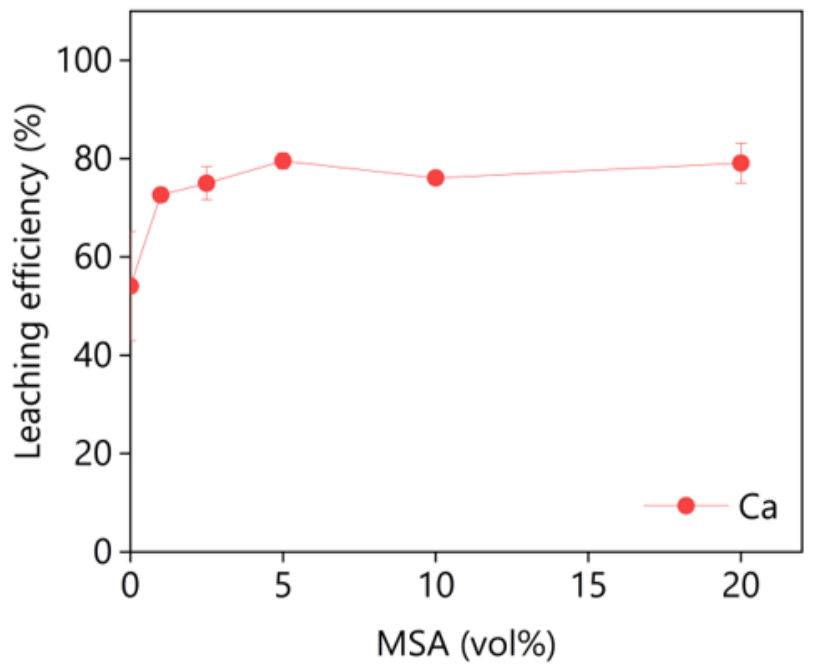

Figure S2: Effect of the MSA concentration on the calcium leaching efficiency from the HALO-free residue. Leaching conditions: $\mathrm{L} / \mathrm{S}(\mathrm{L} / \mathrm{kg})=10 ; \mathrm{t}(\mathrm{min})=120 ; \mathrm{T}\left({ }^{\circ} \mathrm{C}\right)=80$. 


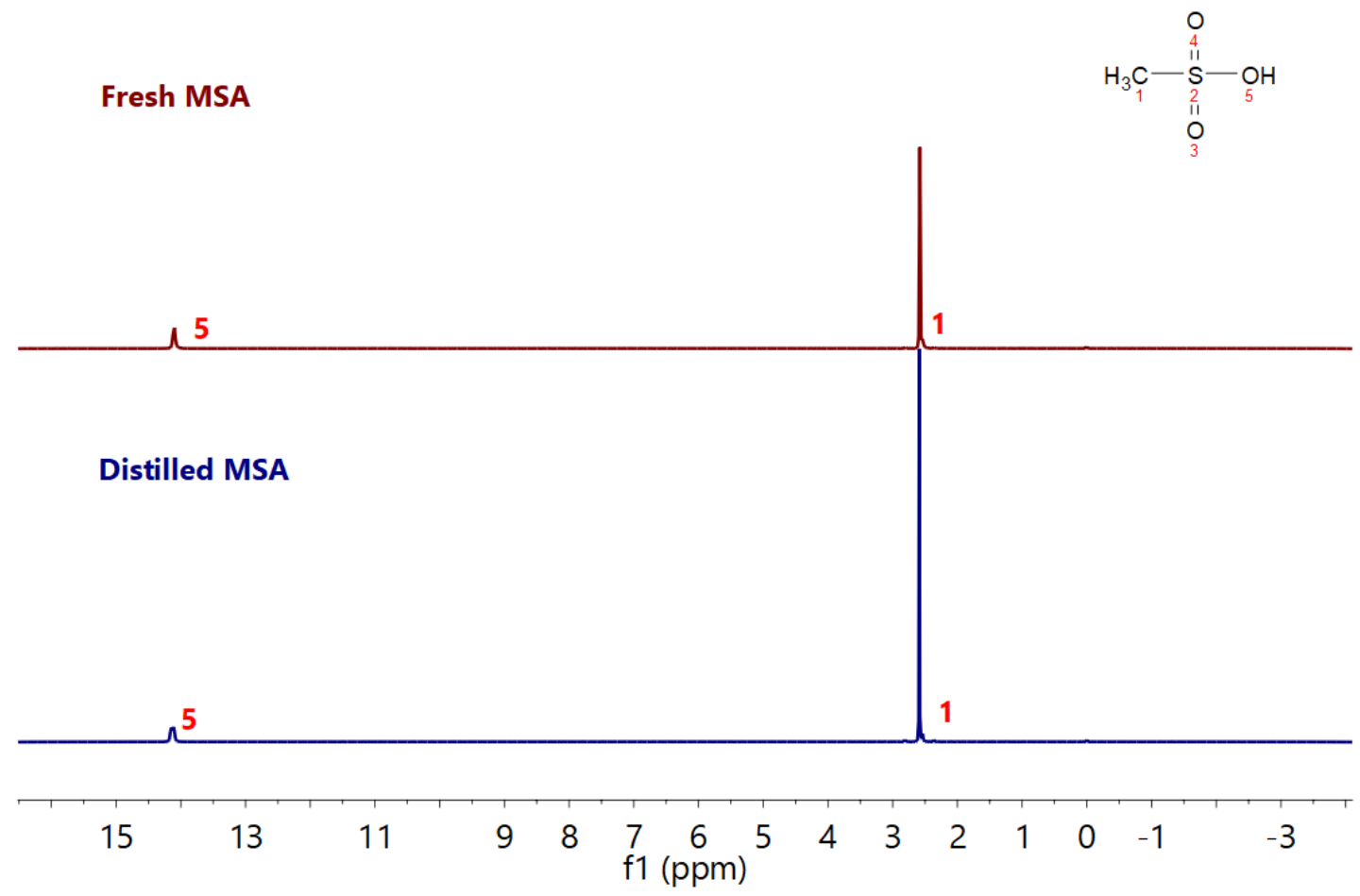

Figure S3: ${ }^{1} \mathrm{H}$ NMR spectra of MSA before (top) and after (bottom) vacuum distillation. Fresh MSA: $\delta$ (ppm): $2.54-2.58\left(3 \mathrm{H}, \mathrm{s}, \mathrm{CH}_{3}\right)$ and $14.10\left(1 \mathrm{H}, \mathrm{s}, \mathrm{SO}_{3} \mathrm{H}\right)$. Distilled MSA $\delta(\mathrm{ppm}): 2.59\left(3 \mathrm{H}, \mathrm{s}, \mathrm{CH}_{3}\right)$ and 14.12(1 $\left.\mathrm{H}, \mathrm{s}, \mathrm{SO}_{3} \mathrm{H}\right)$ 